\section{Short Communication}

\title{
Inhibition of Helicobacter pylori growth in vitro by Bulgarian propolis: preliminary report
}

\author{
Lyudmila Boyanova, ${ }^{1}$ Sirigan Derejian, ${ }^{2}$ Radka Koumanova, ${ }^{3}$ \\ Nikolai Katsarov, ${ }^{4}$ Galina Gergova, ${ }^{1}$ Ivan Mitov, ${ }^{1}$ Rossen Nikolov ${ }^{2}$ \\ and Zacharii Krastev ${ }^{2}$
}

\author{
${ }^{1}$ Department of Microbiology, Medical University of Sofia, Sofia, Bulgaria \\ ${ }^{2}$ Department of Gastroenterology, St Ivan Rilski Hospital, Sofia, Bulgaria \\ ${ }^{3}$ Department of Gastroenterology, Pediatric Hospital, Sofia, Bulgaria \\ ${ }^{4}$ Alexander Hospital, Second Surgery Hospital, Sofia, Bulgaria
}

\begin{abstract}
Bee glue (propolis) possesses antimicrobial, anti-inflammatory, anaesthetic and immunostimulating activities. The aim of the study was to evaluate the inhibitory effect of Bulgarian propolis on Helicobacter pylori growth in vitro. Activity of $30 \%$ ethanolic extract of propolis (EEP) against 38 clinical isolates of $H$. pylori was evaluated by using the agar-well diffusion method. Ethanol was used as a control. In addition, the effect of propolis on the growth of $26 \mathrm{H}$. pylori and 18 Campylobacter strains was tested by the disc diffusion method. Mean diameters of $H$. pylori growth inhibition by the agar-well diffusion method, using 30,60 or $90 \mu \mathrm{l}$ EEP or $30 \mu$ ethanol per well, were $17 \cdot 8,21 \cdot 2,28 \cdot 2$ and $8.5 \mathrm{~mm}$, respectively. EEP was significantly more active than ethanol against $H$. pylori $(P<0.001)$. The results obtained by the disc diffusion method were similar. The use of moist propolis discs resulted in mean diameters of growth inhibition of $21.4 \mathrm{~mm}$ for $H$. pylori and $13.6 \mathrm{~mm}$ for Campylobacterspp. Dried propolis discs exhibited antibacterial effect against $73.1 \%$ of $H$. pylori isolates, with a considerable zone of growth inhibition ( $\geqslant 15 \mathrm{~mm}$ ) in $36.4 \%$ of isolates. Using dried propolis discs resulted in mean diameters of growth inhibition of $12.4 \mathrm{~mm}$ for $H$. pylori and $11.6 \mathrm{~mm}$ for Campylobacter spp. In conclusion, Bulgarian propolis possesses considerable antibacterial activity against $H$. pylori, and can also inhibit the growth of Campylobacter jejuniand Campylobacter coli. The potential of propolis in the prevention or treatment of $H$. pylori infection is worth further extensive evaluation.
\end{abstract}

Received 6 February 2002 Accepted 10 January 2003

\section{Introduction}

Propolis is a resinous product of bees with anti-inflammatory, antimicrobial, anaesthetic and immunostimulating activities (Koo et al., 2000). There are few data concerning the antibacterial activity of bee glue, mainly Brazilian propolis, on Helicobacter pylori (Banskota et al., 2001). However, several studies have reported that propolis has only a limited inhibitory effect against Gram-negative bacilli (Drago et al., 2000), and the chemical composition of bee glue exhibits geographical differences. There are no data about the effect of bee glue on Campylobacter spp. The aim of the study was to assess the inhibitory effect of Bulgarian propolis on the growth of $38 \mathrm{H}$. pylori and 18 Campylobacter clinical isolates in vitro by two methods.

Abbreviations: AWDM, agar-well diffusion method; DDM, disc diffusion method; EEP, ethanolic extract of propolis.

\section{Methods}

Thirty-eight H. pylori and 18 Campylobacter strains (Campylobacter jejuni, $n=10$; Campylobacter coli, $n=8$ ) were included in the study. Stock cultures were maintained in $15 \%$ glycerol broth at $-70{ }^{\circ} \mathrm{C}$. They were subcultured onto Mueller-Hinton agar with $5 \%$ sheep blood and $1 \%$ IsoVitaleX (BBL), and incubated microaerobically at $35^{\circ} \mathrm{C}$ for $48-$ $72 \mathrm{~h}$. Inocula, corresponding to a value of 2 on the McFarland optical density scale, were prepared in Mueller-Hinton broth and were plated onto Mueller-Hinton agar plates in three directions by sterile swabs. The plates were left to dry for $15 \mathrm{~min}$.

Activity of ethanolic extract of Bulgarian propolis (30\% EEP, w/v, Hygitest) was tested against $38 \mathrm{H}$. pylori strains by an agar-well diffusion method (AWDM). Ethanol (96\%) was used as a control. Wells, $7 \mathrm{~mm}$ in diameter, were punched in each agar plate using a sterile stainless steel borer. Each well was filled with 30, 60 or $90 \mu \mathrm{l} 30 \%$ EEP or $30 \mu \mathrm{l} 96 \%$ ethanol. In addition, a disc diffusion method (DDM), using paper discs

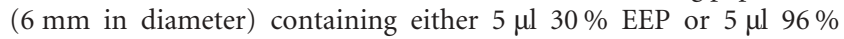
ethanol, was performed for $26 \mathrm{H}$. pylori and 18 Campylobacter strains. Two kinds of disc were used: moist propolis discs were prepared immediately before testing, and dry propolis discs were prepared in the same way and left to dry for 2-3 days. 
The plates, tested by both methods, were incubated microaerobically (Helico-Campy Pack gas-generating envelopes, NCIPD, Bulgaria) at $35^{\circ} \mathrm{C}$ for $72 \mathrm{~h}$. The diameters of inhibitory zones were measured in $\mathrm{mm}$. All isolates were tested in duplicate and mean values of growth inhibition for each strain were taken into account. The $\chi^{2}$ test with Yates' correction was used as a statistical method to determine significance.

\section{Results}

Mean diameters of $H$. pylori growth inhibition by Bulgarian propolis are presented in Table 1. At a volume of $30 \mu \mathrm{l}$ per well, $30 \%$ EEP exhibited greater activity against $H$. pylori than did ethanol (mean diameters of growth inhibition: 17.8 vs $8.5 \mathrm{~mm}, P<0.01)$. At volumes of $90 \mu \mathrm{l}$ EEP per well, around $90 \%$ of $H$. pylori strains exhibited large diameters of growth inhibition ( $\geqslant 15 \mathrm{~mm}$, as shown in Fig. 1), vs $52.6 \%$ by $30 \mu \mathrm{l}$ EEP per well $(P<0 \cdot 01)$. The results obtained by DDM were similar. The activity of moist propolis discs against $H$. pylori was slightly greater than that against Campylobacter isolates (mean inhibitory diameters: 21.4 vs $13.6 \mathrm{~mm}$ ). Seventeen of $26 \mathrm{H}$. pylori isolates $(65 \cdot 4 \%)$ showed considerable growth inhibition ( $\geqslant 15 \mathrm{~mm})$, vs $33 \%(6 / 18)$ of Campylobacter strains $(P>0.05)$. Ethanol exhibited a slight inhibitory effect on $H$. pylori, with inhibitory zone diameters of at least $15 \mathrm{~mm}$ in only $23.1 \%$ of isolates. Although less active than the moist EEP discs, propolis in dried discs retained a residual antibacterial activity, inducing considerable growth inhibition $(\geqslant 15 \mathrm{~mm})$ in $34.6 \%(9 / 26)$ of $H$. pylori strains and in $11 \cdot 1 \%(2 / 18)$ of Campylobacter isolates.

\section{Discussion}

In different propolis samples, various substance combinations are responsible for the antibacterial activity of the bee glue. In Bulgaria and several Mediterranean countries, propolis contains mainly flavonoids and esters of caffeic and ferulic acids (Velikova et al., 2000). In propolis samples from the temperate zone, flavonoids and esters of phenolic acids are known to be associated with antibacterial activity (Kujumgiev et al., 1999). Although the inhibitory effect of propolis on Gram-positive bacteria has been demonstrated, the activity of bee glue against Gram-negative bacteria is a matter of controversy (Drago et al., 2000); for example, propolis has shown good activity against Haemophilus influenzae and Moraxella catarrhalis, but not against Enterobacteriaceae. The anti- $H$. pylori activity of Brazilian propolis

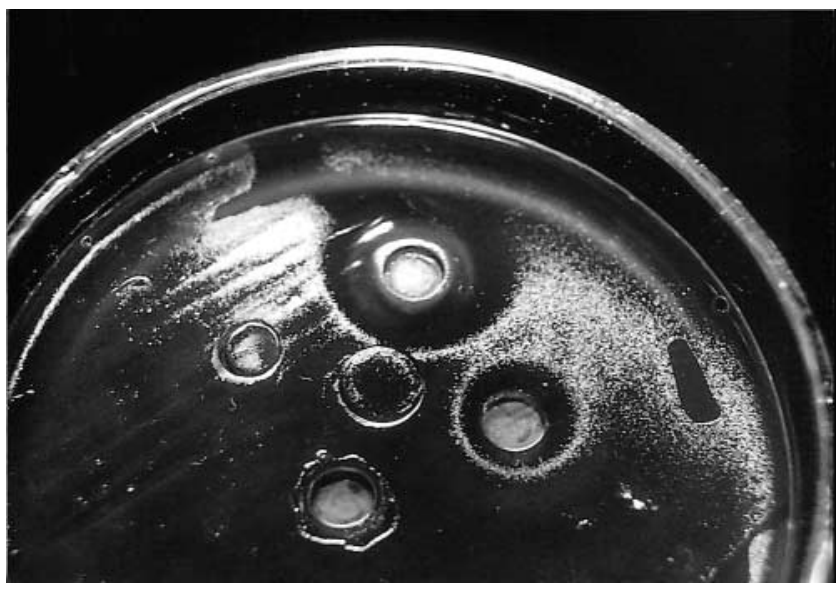

Fig. 1. Inhibitory effect of ethanolic extract of Bulgarian propolis (30\%) on $\mathrm{H}$. pylori growth by AWDM. Note the large inhibitory zone around the well containing $90 \mu$ propolis extract.

has recently been reported, labdane-type diterpenes and some prenylated phenolic compounds being the main antibacterial substances (Banskota et al., 2001).

In the present study, the agar-well diffusion and the disc diffusion methods were used because they have the advantage of showing both inhibition and control growth (outside the inhibitory zone) of fastidious organisms on the same plate. Bulgarian propolis has considerable antibacterial activity against $H$. pylori in vitro: only $21 \%(8 / 38)$ of the strains exhibited no inhibitory zone by AWDM using $30 \mu \mathrm{l}$ EEP per well, and all isolates were inhibited to some extent by $90 \mu \mathrm{l}$ EEP per well. Similar results were obtained by DDM. Only $3.8 \%$ of $H$. pylori strains were not inhibited by moist EEP discs. Mirzoeva et al. (1997) have reported the speciesdependent antibacterial effect of propolis, with some active, but labile, ingredients showing the highest activity. In the present study, the slight activity of dried propolis discs on $H$. pylori and Campylobacter strains, with mean inhibitory zone diameters of 12.4 and $11.6 \mathrm{~mm}$, respectively, also suggests the presence of relatively stable antibacterial compounds.

In conclusion, the eradication of $H$. pylori infection is sometimes difficult because of increasing resistance to clarithromycin and metronidazole, the two major antimicrobial agents used in current triple regimens (Megraud,

Table 1. Antibacterial activity of $30 \%$ EEP and $96 \%$ ethanol against $H$. pylori strains, as measured by AWDM and DDM

\begin{tabular}{|c|c|c|c|c|c|c|c|}
\hline \multirow[t]{2}{*}{ Parameter } & \multicolumn{4}{|c|}{ AWDM (38 H. pylori strains) } & \multicolumn{3}{|c|}{ DDM (26 H. pylori strains) } \\
\hline & $\begin{array}{c}30 \mu \mathrm{l} \text { EEP } \\
\text { per well }\end{array}$ & $\begin{array}{c}60 \mu \mathrm{l} \text { EEP } \\
\text { per well }\end{array}$ & $\begin{array}{c}90 \mu \mathrm{l} \text { EEP } \\
\text { per well }\end{array}$ & $\begin{array}{c}30 \mu l \text { ethanol } \\
\text { per well }\end{array}$ & $\begin{array}{c}5 \mu \mathrm{l} \text { EEP } \\
\text { (moist disc) }\end{array}$ & $\begin{array}{c}5 \mu \mathrm{l} \text { EEP } \\
\text { (dried disc) }\end{array}$ & $\begin{array}{c}5 \mu \mathrm{l} \\
\text { ethanol }\end{array}$ \\
\hline Mean diameter of growth inhibition ( $\mathrm{mm})$ & $17 \cdot 8$ & $21 \cdot 2$ & $28 \cdot 2$ & $8 \cdot 5$ & $21 \cdot 4$ & $12 \cdot 4$ & $9 \cdot 0$ \\
\hline Range (mm) & $7-48$ & $7-56$ & $9-60$ & $7-18$ & $6-40$ & $6-30$ & $6-18$ \\
\hline
\end{tabular}


2000). This motivates the search for alternative or additional therapeutic agents. The inhibitory activity of propolis against $H$. pylori in vitro is worth further bacteriological, pharmacological and clinical evaluation. The use of propolis mouthwashes could reduce or eliminate $H$. pylori in the mouth cavity, as a route of transmission of $H$. pylori infection (Megraud \& Broutet, 2000). The synergistic effect of propolis and several antimicrobial agents (e.g. cloxacillin and doxycycline) has been demonstrated against Staphylococcus aureus (Krol et al., 1993). The presence or lack of synergistic effect of propolis with metronidazole, clarithromycin or amoxicillin against $H$. pylori is worthy of investigation. In addition, the anti-inflammatory and tissue-regenerative properties of propolis (Koo et al., 2000) could be an additional advantage in the prevention or treatment of $H$. pylori infection.

\section{References}

Banskota, A. H., Tezuka, Y., Adnyana, I. K., Ishii, E., Midorikawa, K., Matsushige, K. \& Kadota, S. (2001). Hepatoprotective and antiHelicobacter pylori activities of constituents from Brazilian propolis. Phytomedicine 8, 16-23.

Drago, L., Mombelli, B., De Vecchi, E., Fassina, M. C., Tocalli, L. \& Gismondo, M. R. (2000). In vitro antimicrobial activity of propolis dry extract. J Chemother 12, 390-395.
Koo, H., Gomes, B. P., Rosalen, P. L., Ambrosano, G. M., Park, Y. K. \& Cury, J. A. (2000). In vitro antimicrobial activity of propolis and Arnica montana against oral pathogens. Arch Oral Biol 45, 141-148.

Krol, W., Scheller, S., Shani, J., Pietsz, G. \& Czuba, Z. (1993). Synergistic effect of ethanolic extract of propolis and antibiotics on the growth of Staphylococcus aureus. Arzneim-Forsch 43, 607-609.

Kujumgiev, A., Tsvetkova, I., Serkedjieva, Y., Bankova, V., Christov, R. \& Popov, S. (1999). Antibacterial, antifungal and antiviral activity of propolis of different geographic origin. J Ethnopharmacol 64, 235-240.

Megraud, F. (2000). Strategies to treat patients with antibiotic resistant Helicobacter pylori. Int J Antimicrob Agents 16, 507-509.

Megraud, F. \& Broutet, N. (2000). Review article: have we found the source of Helicobacter pylori? Aliment Pharmacol Ther 14 (Suppl. 3), 712.

Mirzoeva, O. K., Grishanin, R. N. \& Calder, P. C. (1997). Antimicrobial action of propolis and some of its components: the effect on growth, membrane potential and motility of bacteria. Microbiol Res 152, 239246.

Velikova, M., Bankova, V., Sorkun, K., Houcine, S., Tsvetkova, I. \& Kujumgiev, A. (2000). Propolis from the Mediterranean region: chemical composition and antimicrobial activity. Z Naturforsch $[C]$ 55, 790-793. 